\title{
Desenvolvimento e Construção de um Sistema de Baixo Custo para Caracterização de Células Solares Sensibilizadas por Corantes Orgânicos
}

\section{Daniel da Motta Sampaio}

Programa de Pós Graduação em Engenharia Elétrica, CEFET/RJ, Rio de Janeiro, RJ

\section{Elumalai Thirumal ${ }^{2}$}

Programa de Pós Graduação em Engenharia Elétrica, CEFET/RJ, Rio de Janeiro, RJ

\author{
Ana Lucia Ferreira de Barros ${ }^{3}$ \\ Programa de Pós Graduação em Engenharia Elétrica, CEFET/RJ, Rio de Janeiro, RJ
}

\begin{abstract}
Resumo. Este trabalho descreve a construção de um sistema de baixo custo para caracterização de células solares sensibilizadas por corantes orgânicos (DSSC's). Apresentaremos as curvas geradas e parâmetros de eficiência e performance obtidos através da integração do sistema utilizando um módulo de aquisição de dados.
\end{abstract}

Palavras-chave. DSSC's, Células Fotovoltaicas, Caracterização IV, Sistemas de Aquisição de Dados, Instrumentação Eletrônica

\section{Introdução}

Uma vez que a demanda por energia é crescente no planeta, buscam-se alternativas para o desenvolvimento de fontes energéticas sustentáveis, eficientes e de baixo custo, como a conversão de energia solar em energia elétrica através de células fotovoltaicas. A energia solar fotovoltaica aparece então como uma maneira viável de uso de energia renovável, apesar dos custos serem maiores comparados a outras fontes. Estes custos de produção têm diminuído ao longo dos anos e tem-se buscado o desenvolvimento de células solares mais baratas e eficientes, como as células solares sensibilizadas por corantes orgânicos (DSSC's - Dye Sensitized Solar Cells) [1]. As DSSC's são compostas por estruturas semicondutoras nanoestruturadas, sobre as quais é feita a aplicação de um corante orgânico, que terá a função de absorver os fótons de luz e, uma vez que os mesmos

${ }^{1}$ mottasampaio@gmail.com

2esthirumal@gmail.com

33abarros@pq.cnpq.br 
sejam excitados, transferirão elétrons até a superfície condutora, obtendo assim o efeito fotovoltaico [2].

Após a construção e montagem das DSSC's (o processo experimental de construção das DSSC's não será detalhado neste trabalho), deve ser feita a caracterização das mesmas, a fim de se realizar a modelagem das células construídas e verificar os valores de tensão, corrente e potência obtidos, determinando-se assim os principais parâmetros das células construídas, tais como eficiência e pontos de operação com máxima transferência de potência.

Este trabalho está sendo desenvolvido no Laboratório de Física Experimental e Aplicada (LaFEA) no CEFET/RJ, onde um sistema para a caracterização das DSSC's está sendo construído. Para tal é necessário ter um ambiente controlado, em relação à irradiância da luz solar incidente, temperatura das amostras e que não houvesse contato direto com as células durante a realização dos ensaios. Os parâmetros de eficiência e performance das DSSC's foram adquiridos em tempo real, uma vez que o sistema foi integrado a um módulo de aquisição de dados (DAQ), que oferece medições de corrente e tensão, além de integração com o software Labview ${ }^{\circledR}$, de maneira a obter em tempo real os parâmetros necessários e gerar as curvas de performance das DSSC's.

Através deste sistema podemos simular a incidência de radiação solar sobre uma DSSC, mantendo a amostra resfriada a temperatura ambiente, evitando que variações de temperatura influam nos valores obtidos de corrente e tensão. O sistema possui bornes onde podemos ligar a fonte de tensão e os instrumentos de medidas, sem entrar em contato direto com as células. Também foi necessário a construção de um sistema de resfriamento para controlar a temperatura das amostras.

A radiação incidente sobre a célula pode ser controlada através de uma fonte de tensão regulável aplicada a uma lâmpada de corrente contínua. Diversas situações de irradiância e temperatura podem ser simuladas, garantindo medidas mais confiáveis e ampliando o estudo das DSSC's.

\section{Objetivos}

O objetivo deste trabalho é a construção de um sistema de caracterização de células solares de baixo custo, e particularmente, obter-se os parâmetros de performance e potência relativos às DSSC's fabricadas em nosso laboratório.

As células solares sensibilizadas por corantes orgânicos (DSSC's) surgem como uma opção viável de células solares de baixo custo e de boa eficiência, que podem ser desenvolvidas utilizando os filmes finos feitos através de diversos óxidos metálicos, tais como o $\mathrm{Nb}_{2} \mathrm{O}_{5}$ (Pentóxido de Nióbio) e $\mathrm{TiO}_{2}$ (Dióxido de Titânio).

Após a montagem das células, as eficiências das mesmas, bem como as suas características elétricas, devem ser determinadas. Esses dados podem ser obtidos através das curvas de tensão/corrente e de potência das células individuais ou conjunto de células, em arranjos série ou paralelo.

As curvas geradas através do sistema integrado de caracterização e aquisição de dados implementado podem ser comparadas com curvas obtidas nos instrumentos tradicionais de medição, tais como multímetros e osciloscópios e também através de sistemas mais complexos, como simuladores solares. 


\section{Procedimento Experimental}

Este trabalho envolve a construção e montagem das células solares sensibilizadas por corantes orgânicos (DSSC's), além do desenvolvimento de um sistema de caracterização de baixo custo, de maneira a realizar a modelagem do dispositivo e determinar suas características.

Uma célula fotovoltaica, ao ser sensibilizada pela ação dos fótons sobre a mesma, produz entre seus terminais uma diferença de potencial. Ao conectarmos uma carga a esta célula, será gerada uma fotocorrente, e assim teremos um circuito equivalente semelhante ao de uma fonte de corrente em paralelo com um diodo, associado às resistências parasitas série $\left(\mathrm{R}_{\mathrm{s}}\right)$ e paralelo ou shunt $\left(\mathrm{R}_{\mathrm{sh}}\right)$ [3].

Para medirmos os valores de corrente e tensão foi utilizado o Sistema de Aquisição de Dados cDAQ-9188, da National Instruments. Acoplado a este chassi estão os módulos NI9201 e NI-9203, de 8 canais para entradas analógicas, utilizados para medições de tensão e corrente. $\mathrm{O}$ circuito equivalente resumido do sistema pode ser visto na Figura 1.

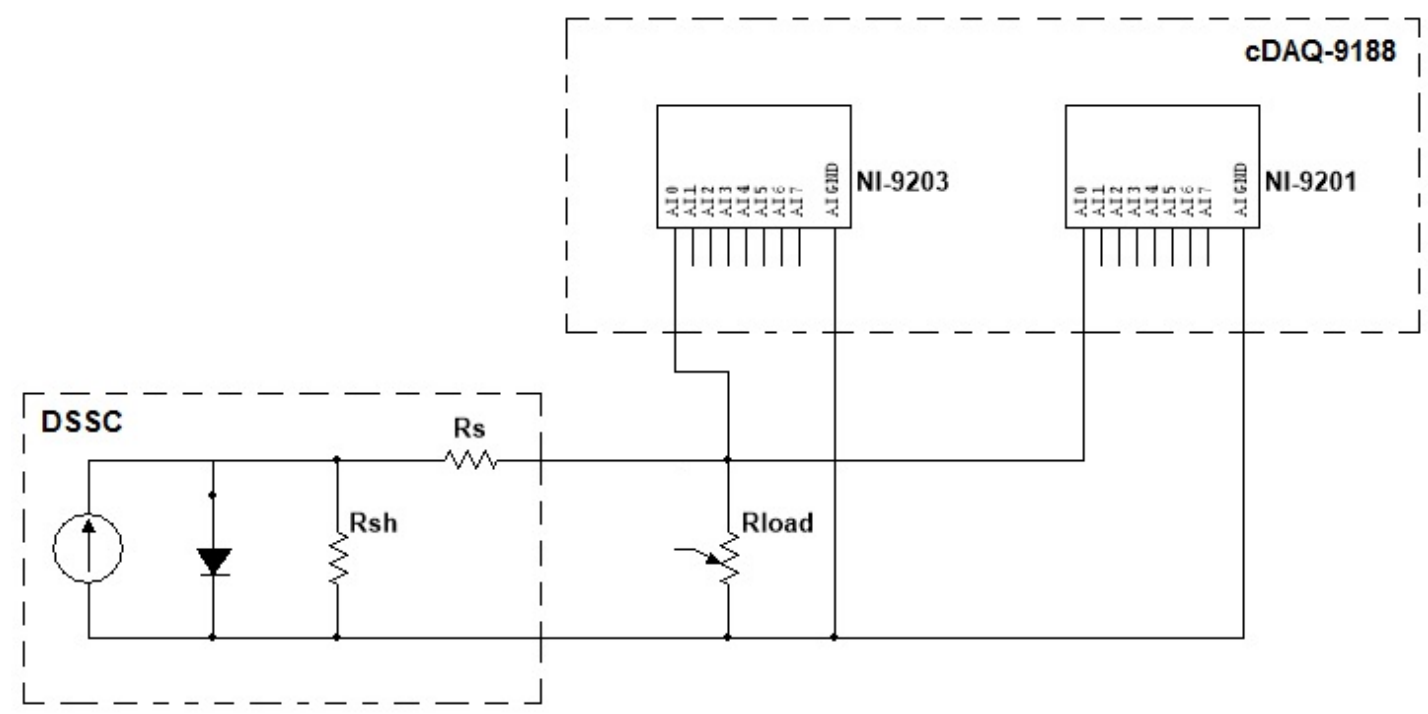

Figura 1: Circuito equivalente do sistema.

Um dos principais parâmetros a ser observado na caracterização de uma célula fotovoltaica é a sua curva de tensão X corrente (Curva I X V - Figura 2a), que pode ser obtida experimentalmente variando-se a carga aplicada sobre a célula ou podendo também ser estimada matematicamente. 

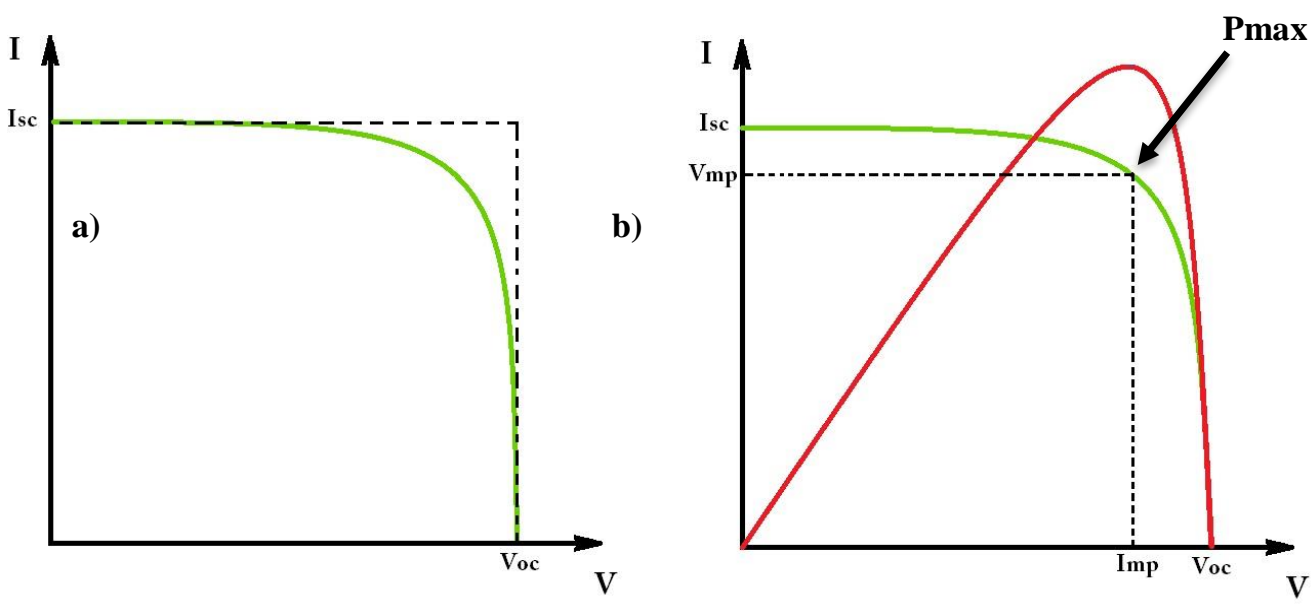

Figura 2: Curvas típicas de tensão versus corrente (verde) e potência versus tensão (vermelha).

Uma vez traçada a curva I X V, podemos caracterizar a célula solar e determinar os seus principais parâmetros, tais como: tensão de circuito aberto, corrente de curto-circuito, fator de preenchimento e rendimento. A tensão de circuito aberto $\mathrm{V}_{\mathrm{oc}}$ é a máxima tensão gerada pelo dispositivo fotovoltaico, e pode ser obtida experimentalmente medindo-se a tensão nos terminais de uma célula sem carga, sob determinadas condições de temperatura e radiação incidentes. A corrente de curto-circuito $\left(\mathrm{I}_{\mathrm{sc}}\right)$ é a máxima corrente que a célula solar pode fornecer, e pode ser obtida curto-circuitando os terminais da célula e medindo a corrente que flui através do dispositivo.

Ao acoplarmos uma carga a um dispositivo fotovoltaico, a partir do momento que a resistência da carga for aumentando, a potência de saída também aumentará, de maneira que, comparando-se com a curva I x V, teremos um ponto de interseção entre ambas. Este ponto é conhecido como Ponto de Máxima Potência $\left(\mathrm{P}_{\max }\right)$, que pode ser definido como sendo o ponto de maior eficiência energética de uma célula solar e deve ser buscado por sistemas de controle de potência associados aos dispositivos de geração de energia fotovoltaica. Os valores de tensão e corrente no ponto de máxima potência são denotados por $\mathrm{V}_{\mathrm{mp}}$ e $\mathrm{I}_{\mathrm{mp}}$, respectivamente, conforme pode ser visto na Figura $2 \mathrm{~b}$.

O sistema de caracterização foi desenvolvido com a finalidade de possibilitar o levantamento das curvas de performance de uma DSSC. Para simular a irradiância solar, foi utilizado uma lâmpada de corrente contínua de $55 \mathrm{~W}$, cuja tensão aplicada sobre a mesma foi controlada utilizando-se a fonte de tensão regulável PS5100, da Icel.

O resfriamento das amostras é realizado utilizando tubos de cobre, que circulam água fria, situados abaixo da base cerâmica onde as células são colocadas para a caracterização. Para as medições de corrente e tensão e levantamento das curvas foi utilizado o sistema de aquisição de dados cDAQ-9188, com os módulos NI-9201 e NI-9203 acoplados ao mesmo. A interface entre software e hardware foi implementada via rede ETHERNET. Um módulo específico da National Instruments foi utilizado para a caracterização de células solares (detalhes na ref.[4]). Um esquema geral do sistema utilizado é apresentado na Figura 3. 


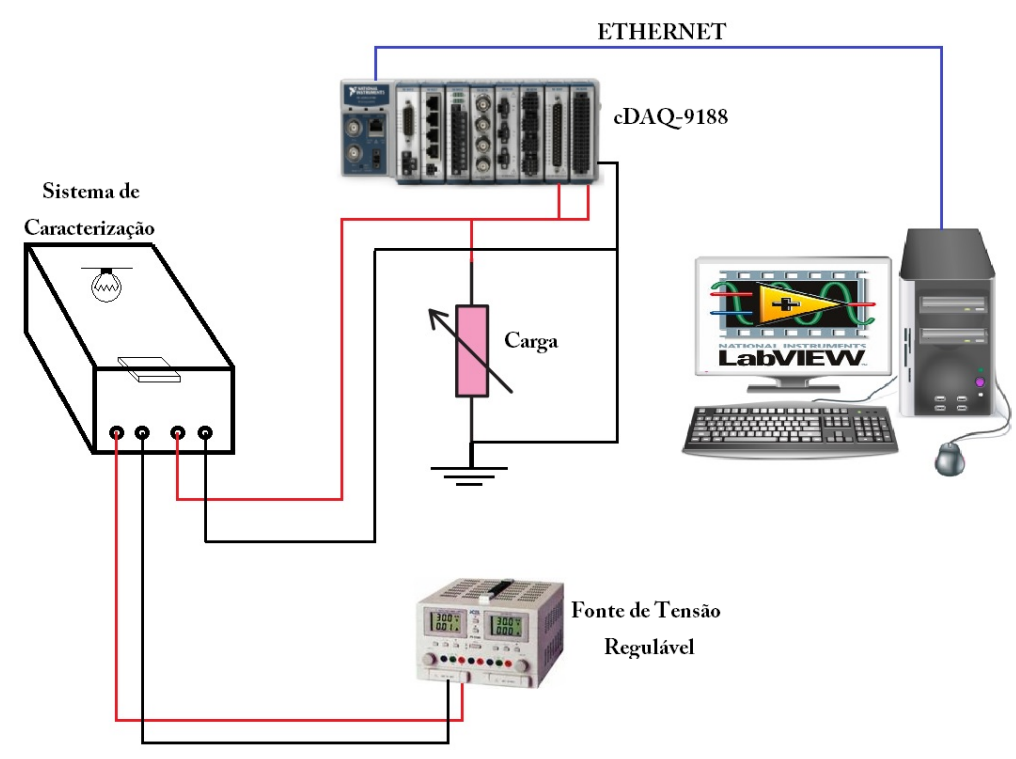

Figura 3: Esquema do sistema de caracterização montado no LaFEA.

\section{Resultados}

Utilizando-se o sistema de caracterização foram geradas curvas para diferentes situações, de maneira a compararmos a eficiência das células para diferentes casos. Para os testes apresentados neste trabalho, foi utilizada uma célula solar com corante o suco de jabuticaba, que apresentou melhores valores de tensão máxima $(660 \mathrm{mV})$. A carga foi simulada utilizando-se um potenciômetro de $100 \mathrm{k} \Omega$. Os dados foram coletados em tempo real através do aplicativo Signal Express, no Labview ${ }^{\circledR}$, que foram gravados e carregados no Toolkit utilizado para a caracterização de células fotovoltaicas.

A frequência e o número de amostras coletadas foram variados, de maneira a verificarse qual condição seria mais satisfatória para a geração das curvas. Pôde-se observar que para um grande número de amostras medidas, as curvas geradas diferiram muito do que era esperado. Um dos motivos para essa discrepância de valores é a sensibilidade do módulo de medição, pois uma vez que os valores de tensão e corrente coletados são muito baixos, estes podem ser confundidos com ruídos de comunicação, e uma vez carregados e plotados, geram resultados insatisfatórios.

A Figura 4 ilustra uma caracterização feita para a célula utilizando-se a frequência de $10 \mathrm{~Hz}$ no aplicativo Labview ${ }^{\circledR}$, onde pode-se obter diretamente os valores dos parâmetros de performance e potência, através de cálculos que são executados baseados nas curvas geradas e nos valores obtidos. Estas curvas foram geradas para a célula sem e com iluminação. Os valores obtidos são apresentados nos gráficos da Figura 5 para maior clareza. Variando-se a intensidade de radiação incidente sobre a célula e a medida da área da mesma, podemos determinar também a eficiência das células testadas.

Como podemos observar, estas curvas se aproximam a uma curva I X V real (Figura 2), de maneira que é possível verificar a viabilidade do sistema de caracterização que estamos desenvolvendo. 

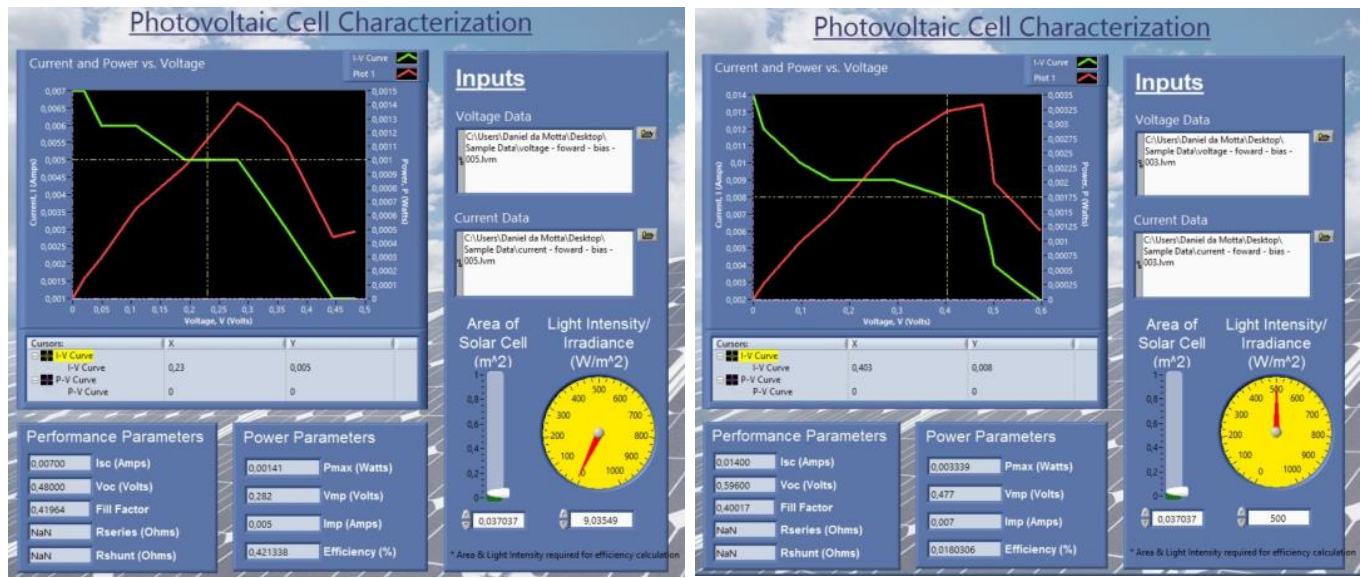

Figura 4: Caracterização de uma célula fotovoltaica.
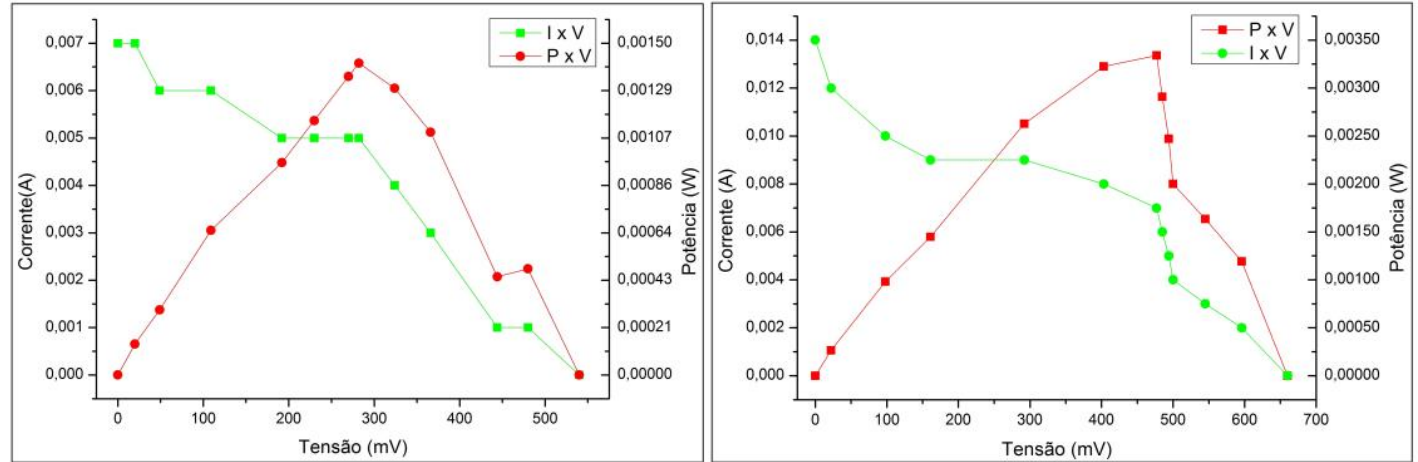

Figura 5: Gráficos I X V e P X V extraídos do software de caracterização.

\section{Conclusões}

Através da realização dos ensaios e a montagem do sistema desenvolvido, pudemos verificar que o sistema pode ser utilizado para a caracterização das células solares, de maneira que todo o processo, da construção das células até a caracterização nas mesmas pôde ser feito em laboratório, em um sistema de baixo custo e de complexidade relativamente baixa, tornando-se uma ferramenta bastante didática e também de fácil implementação.

O objetivo principal do trabalho era compor um sistema de baixo custo e que pudesse efetivamente nos fornecer os parâmetros necessários para a caracterização das novas células solares, em especial as células sensibilizadas por corantes orgânicos (DSSCs), que estão sendo desenvolvidas no nosso laboratório. Foi possível então realizar-se tal estudo, auxiliando-se assim as pesquisas e desenvolvimento de células solares de baixo custo e 
que podem ser construídas de forma relativamente simples.

Espera-se, portanto, com esse projeto, desenvolver e caracterizar células solares acessíveis e economicamente viáveis, de maneira que seja possível realizar futuramente a montagem de paineis ou pequenos módulos solares.

Como projetos futuros, estaremos realizando a comparação dos ensaios realizados com o sistema de caracterização desenvolvido e os resultados obtidos através de um simulador solar, de maneira a verificar se há grandes variações entre os resultados obtidos no experimento.

\section{Agradecimentos}

Os autores agradecem à diretoria de pesquisa e pós-graduação do CEFET/RJ pelo apoio no desenvolvimento da pesquisa, bem como os alunos de iniciação científica e técnicos que auxiliaram nas pesquisas, estudos e experimentos realizados no Laboratório de Física Experimental e Aplicada (LaFEA). Ao CNPq, CAPES e FAPERJ pelo apoio financeiro.

\section{Referências}

[1] J. S. Agnaldo et al., Células solares de $\mathrm{TiO}_{2}$ sensibilizado por corante, Revista Brasileira de Ensino de Física, vol. 28, 77-84, (2006), DOI: 10.1590/S1806-11172006000100010.

[2] M. Grätzel and B. O'Regan, A low-cost, high-efficiency solar cell based on dye-sensitized colloidal $\mathrm{TiO}_{2}$ films, Nature, vol. 353, 737-740, (1991), DOI: 10.1038/353737a0.

[3] Photovoltaic Cell I-V Characterization Theory and LabVIEW Analysis Code, Tutorial, National Instruments, (2012).

[4] T. B. Teixeira, Influência da temperatura em aglomerados auto-reconfiguráveis de células fotovoltaicas, Monografia, Programa de Pós-Graduação em Física, UFMG, (2008). 